\title{
Hepatic Flavin-Containing Monooxygenase 3 Enzyme Suppressed by Type 1 Allergy-Produced Nitric Oxide
}

\author{
Tadatoshi Tanino, Toru Bando, Akira Komada, Yukie Nojiri, Yuna Okada, Yukari Ueda, \\ and Eiichi Sakurai
}

Faculty of Pharmaceutical Sciences, Tokushima Bunri University, Tokushima, Japan

Received May 5, 2017; accepted July 21, 2017

\begin{abstract}
Flavin-containing monooxygenases (FMOs) are major mammalian non-cytochrome P450 oxidative enzymes. T helper 2 cell-activated allergic diseases produce excess levels of nitric oxide (NO) that modify the functions of proteins. However, it remains unclear whether allergy-induced NO affects the pharmacokinetics of drugs metabolized by FMOs. This study investigated alterations of hepatic microsomal FMO1 and FMO3 activities in type 1 allergic mice and further examined the interaction of FMO1 and FMO3 with allergy-induced $\mathrm{NO}$. Imipramine (IMP; FMO1 substrate) $\mathbf{N}$-oxidation activity was not altered in allergic mice with high serum NO and immunoglobulin E levels. At 7 days after primary sensitization (PS7) or secondary sensitization (SS7), benzydamine (BDZ; FMO1 and FMO3 substrate) $\mathrm{N}$-oxygenation was significantly decreased to $70 \%$ of individual controls. The expression levels of FMO1 and FMO3 proteins were not significantly
\end{abstract}

changed in the sensitized mice. Hepatic inducible NO synthase (iNOS) mRNA level increased 5-fold and 15-fold in PS7 and SS7 mice, respectively, and hepatic tumor necrosis factor- $\alpha$ levels were greatly enhanced. When a selective iNOS inhibitor was injected into allergic mice, serum NO levels and BDZ $N$-oxygenation activity returned to control levels. NO directly suppressed BDZN-oxygenation, which was probably related to FMO3-dependent metabolism in comparison with IMP N-oxidation. In hepatic microsomes from PS7 and SS7 mice, the suppression of BDZ $\mathbf{N}$-oxygenation was restored by ascorbate. Therefore, type 1 allergic mice had differentially suppressed FMO3dependent BDZ $\mathrm{N}$-oxygenation. The suppression of FMO3 metabolism related to reversible S-nitrosyl modifications of iNOS-derived NO. NO is expected to alter FMO3-metabolic capacity-limited drug pharmacokinetics in humans.

\section{Introduction}

Flavin-containing monooxygenases (FMOs) are major mammalian non-cytochrome P450 oxidative enzymes (Rettie et al., 1995) that commonly react to form $N$ - and $S$-oxides of nucleophilic hetero-atomcontaining drugs and xenobiotics. Five FMO forms have been identified in humans and mice, and they require NADPH and oxygen. FMO expression is species-, tissue-, age-, and gender-dependent. Of interest, FMO1 form is found in the fetal human liver; however, marked changes in enzyme expression at birth result in FMO3 becoming the predominant human FMO (Dolphin et al., 1996; Koukouritaki et al., 2002). In male and female mice, the FMO1 protein is expressed at a high level, and hepatic FMO3 protein is gender-specific to females (Cherrington et al., 1998). Sex hormones in rats and mice regulate FMO1 and FMO3 expression (Dannan et al., 1986; Lemoine et al., 1991; Falls et al., 1997; Coecke et al., 1998), and glucocorticoids and 17 $\beta$-estradiol are considered to be regulators of gene transcription in rodents and humans (Dixit and Roche, 1984; Esposito et al., 2014). FMO3 exists at levels similar to the major human liver cytochrome P450 CYP3A4 (Haining et al., 1997). Loss-of-function mutations, nonsense mutations, and missense mutations in the FMO3 gene produce phenotypes associated with the inherited disorder trimethylaminuria (Treacy et al., 1998).

https://doi.org/10.1124/dmd.117.076570.
FMO4 protein is expressed in liver of humans and mice (Novick et al., 2009); however, FMO4 does not contribute significantly to drug metabolism in humans (Krueger and Williams, 2005). Functional FMO2 is not expressed in liver of most humans (Dolphin et al., 1998). FMO5 is highly expressed in the liver of mice (Janmohamed et al., 2004) and humans (Cashman and Zhang, 2006). Only a few chemicals are known to be metabolized by mouse FMO5 (Zhang et al., 2007) and the contribution of FMO5 to liver xenobiotic metabolism is not clear. Therefore, FMO1 and FMO3 are considered to be the most important isoforms of the FMO family with respect to the metabolism of foreign chemicals (Ziegler, 1993).

Type I allergic diseases, such as atopic dermatitis, asthma, and allergic rhinitis, are a significant health problem. Approximately $20 \%$ of the world's population suffers from some kind of allergic disorder, with incidences continuing to rise (Warner et al., 2006). Concerning the allergy-inducing mechanism, T helper 2 cytokines (IL-4, IL-5 and IL-13) stimulate mast cells and eosinophils and increase allergen-specific immunoglobulin (Ig)E production. Subsequently, activated mast cells release cytokines and some inflammatory mediators (Zhu et al., 1999; Stassen et al., 2001). Patients with bronchial asthma and allergic rhinitis show an increased level of nitric oxide (NO) in exhaled air (Alving et al., 1993; Kharitonov et al., 1997). We also found that type 1 allergy with high serum IgE concentrations enhance serum NO concentrations (Tanino et al., 2016). Park et al. (1999) suggested that excessive activation of the

ABBREVIATIONS: AG, aminoguanidine; AS, L-ascorbate; BDZ, benzydamine; eNOS, endothelial nitric oxide synthase; FMO, flavin-containing monooxygenase; HPLC, high-performance liquid chromatography; ICR, imprinting control region; IgE, immunoglobulin E; IMP, imipramine; iNOS, inducible nitric oxide synthase; LPS, lipopolysaccharide; NO, nitric oxide; NOC7, 1-hydroxy-2-oxo-3-(N-methyl-3-aminopropyl)-3-methyl-1-triazene; NOx, nitrate plus nitrite; OVA, ovalbumin; P450, cytochrome P450; PS7, 7 days after primary sensitization; SS7, 7 days after secondary sensitization; TNF- $\alpha$, tumor necrosis factor $\alpha$. 
L-arginine/NO pathway (NO-dependent pathway) was responsible for the suppression of FMO activities. However, their findings showed that NO did not react with the flavin adenine dinucleotide prosthetic group of FMO enzymes. The result differs from the formation of iron-nitrosyl complexes in P450 enzymes (Minamiyama et al., 1997). Since FMO3 contains 11 cysteines, one possibility remains that NO participates in $S$-nitrosylation and/or nitration of FMO proteins, leading to consequent reversible and/or irreversible modulation(s) of FMO activity. Concerning the contribution of $\mathrm{T}$ helper 2 cell-activated immune systems, little information is available on the ability of cytokines to directly regulate FMO1 and FMO3 expression. We reported that CYP1A2, CYP2C, CYP2E1, and CYP3A activities were markedly suppressed by allergy-induced NO production-but not the cytokine-dependent pathway-resulting in marked changes in drug pharmacokinetics (Tanino et al., 2016). Our results differed from the significant contribution of $\mathrm{T}$ helper 1 cellactivated proinflammatory cytokines (cytokine-dependent pathway) in lipopolysaccharide-stimulating inflammatory diseases (Renton 2001, 2004; Morgan et al., 2008). Therefore, the main aim of this study was to examine the interaction of hepatic FMO1 and FMO3 enzymes with IgE-mediated allergy-induced NO.

\section{Materials and Methods}

Materials. Benzydamine (BDZ) was purchased from Tokyo Kasei Co., Ltd. (Tokyo, Japan). L-Ascorbate (AS; effective on S-NO binding), Bordetella pertussis inactive bacterial suspension, and aminoguanidine (AG) were purchased from Nacalai Tesque Co. (Kyoto, Japan). Aluminum hydroxide gel (alhydrogel) was obtained from InvivoGen (San Diego, CA). Imipramine (IMP) and amitriptyline were obtained from Wako Pure Chemicals (Osaka, Japan). Chicken egg albumin (OVA) was obtained from Sigma-Aldrich (St. Louis, MO). Talinolol, IMP $N$-oxide and BDZ $N$-oxide were purchased from Toronto Research Chemicals Inc. (North York, ON, Canada). 1-Hydroxy-2-oxo-3-( $N$-methyl-3-aminopropyl)-3-methyl-1triazene (NOC7) was obtained from Dojin Co. (Kumamoto, Japan). $\beta$-Nicotinamide adenine dinucleotide $2^{\prime}$-phosphate-reduced tetrasodium $\left(\beta\right.$-NADP $\left.{ }^{+}\right)$, glucose6-phosphate dehydrogenase, and glucose-6-phosphate were obtained from Oriental Yeast Co. Ltd. (Tokyo, Japan). All other chemicals used were of analytical grade and commercially available.

Animals and Treatments. Female imprinting control region (ICR) mice (Japan SLC Co., Shizuoka, Japan), weighing 15-20 g, were housed under standard conditions (light/dark cycle of 12 hours; room temperature of $23^{\circ} \mathrm{C} \pm 1{ }^{\circ} \mathrm{C}$ ) and provided with food and water ad libitum. For establishment of IgE-mediated allergic animals, mice (age, 6 weeks; weight range, 18-22 g) were sensitized with an intraperitoneal injection of a mixture containing $5 \mu \mathrm{g}$ OVA, $2 \mathrm{mg}$ aluminum hydroxide gel, and $B$. pertussis inactive bacterial suspension $\left(2 \times 10^{9}\right.$ cells) on day 0 according to the methods described by Pauwels et al. (1979) and Lebrec et al. (1996). On day 8, the mice were challenged with $2.5 \mu \mathrm{g}$ OVA $(250 \mu \mathrm{g} / \mathrm{ml}$ of saline) by intravenous injection. Control mice were given single intraperitoneal and intravenous injections of saline. At 7 days after the primary and secondary sensitization (PS7 and SS7, respectively), mice were sacrificed by decapitation. Blood was collected in heparinized tubes, and plasma was separated by centrifugation at $3000 \mathrm{rpm}$ for 10 minutes. The liver was excised and washed three times with ice-cold $50 \mathrm{mM}$ Tris-HCl (pH 7.4). Further treatments for high-performance liquid chromatography (HPLC) assay were detailed in our recent study (Tanino et al., 2016). All animal experiments were approved by the Tokushima Bunri University Faculty of Pharmaceutical Sciences' Committee for the care and use of laboratory animals.

In separate experiments, PS7 and SS7 mice were repeatedly injected with AG $(100 \mathrm{mg} / \mathrm{kg}$ per day, i.p.) from day 2 to day 7 or to day 14 after the primary sensitization. The AG dosage was determined by the in vivo data reported by Okuda et al. (1998). The body weight of AG-treated mice did not differ from that of control mice receiving only saline (data not shown).

Assay of Total Plasma IgE and Serum NO Levels. Total plasma IgE levels were measured by enzyme-linked immunosorbent assay using a commercially available mouse IgE ELISA Kit (Shibayagi, Gunma, Japan) according to the manufacturer's instructions. The absorbance was measured at $450 \mathrm{~nm}$ using a microplate reader.
Serum concentrations of $\mathrm{NO}_{2}^{-}$were determined using a Nitrate/Nitrite Colorimetric Assay Kit (Cayman Chemical, Ann Arbor, MI) according to the manufacturer's instructions. The assay conditions were detailed in our recent report (Tanino et al., 2016).

Enzyme Assay. Liver microsomes from control and treated mice were prepared as described previously (Tanino et al., 2016). Protein concentrations were determined with a BCA Protein Assay Kit (Thermo Fisher Scientific Inc., Rockford, IL) and bovine serum albumin as a protein standard. Aliquots of microsomes were stored at $-80^{\circ} \mathrm{C}$ until analysis.

Hepatic FMO1 and FMO3 activities were determined by measuring the $N$-oxide formation of IMP and BDZ (Narimatsu et al., 1999; Ubeaud et al., 1999). The incubation mixtures $(400 \mu \mathrm{l})$ contained liver microsomal protein (final protein concentration, $0.5 \mathrm{mg} / \mathrm{ml}$ for IMP metabolism, $0.1 \mathrm{mg} / \mathrm{ml}$ for BDZ metabolism) from control (saline) and treated mice, an NADPH-generating system $\left(0.2 \mathrm{mM} \mathrm{NADP}^{+}, 28.6 \mathrm{mM} \mathrm{MgCl} 2,11.4 \mathrm{mM}\right.$ glucose-6-phosphate and $20 \mathrm{IU} / \mathrm{ml}$ glucose-6-phoshate dehydrogenase), and FMO substrate (20 $\mu \mathrm{M}$ IMP, or $0.5 \mu \mathrm{M} \mathrm{BDZ}$ ). All enzymatic reactions were initiated by the addition of the $\mathrm{NADPH}$-generating system and were allowed to proceed at $37^{\circ} \mathrm{C}$ for different times ( 5 minutes for IMP and 2 minutes for BDZ). Each reaction was stopped with ice-cold acetonitrile containing amitriptyline and talinolol as internal standards in a HPLC assay of IMP and BDZ, respectively. Sodium hydroxide $0.1 \mathrm{~N}$ was added to the mixture. Subsequently, $N$-oxides of IMP and BDZ were extracted in ethyl acetate (Narimatsu et al., 1999) and chloroform (Ubeaud et al., 1999), respectively, and then centrifuged at $3000 \mathrm{rpm}$ for 10 minutes. After evaporating the organic layers, the residues were reconstituted in each mobile phase used for HPLC analysis and loaded on HPLC columns. FMO activities were expressed as metabolic formation rates of IMP $N$-oxide and BDZ $N$-oxide. Our preliminary study confirmed that the incubation time, substrate concentration, and amount of microsomes were determined to be in the linear range for metabolite formation rate.

To examine the direct interaction of hepatic microsomal FMO enzymes with $\mathrm{NO}$, in vitro experiments were performed according to the method reported by Minamiyama et al. (1997). Briefly, an efficient NO donor, NOC7 dissolved in $0.1 \mathrm{~N} \mathrm{NaOH}$, was added to the microsomes and NADPH-generating system at a final concentration of $1 \mathrm{mM}$. The same volume of vehicle (final concentration, $0.025 \% \mathrm{NaOH}$ for $\mathrm{NOC} 7$ treatment) was added as the reference. According to the method reported by Ryu et al. (2004), the pretreated microsomes were exposed to $\mathrm{AS}$ at a final concentration of $10 \mathrm{mM}$. After the AS exposure, BDZ $N$-oxygenation was assayed under the conditions described above.

In separate experiments, we examined $S$-nitrosylation of hepatic microsomal FMO1 and FMO3 enzymes in PS7 and SS7 mice. Hepatic microsomes from PS7 and SS7 mice were pretreated with $10 \mathrm{mM}$ AS in the presence of the NADPHgenerating system. Subsequently, BDZ was added, and the reaction mixtures were incubated for 5 minutes. Our preliminary study on $S$-nitrosylated FMO enzymes confirmed that NOC7 concentration, AS concentration, exposure time, substrate concentration, and amount of microsomes were determined to be in the linear range for the metabolite formation rate.

Immunoblotting. FMO1 and FMO3 protein levels in mouse liver microsomes were determined by SDS-PAGE followed by Western blotting. In brief, hepatic microsomal proteins $(50 \mu \mathrm{g})$ were separated by $7.5 \%$ SDS-PAGE and transferred electrophoretically. Proteins were transferred onto Immobilon-P transfer membranes (Millipore Corporation, Billerica, MA). Membranes were blocked with Blocking One (Nacalai Tesque) and then incubated with rabbit polyclonal antibody human FMO1 (cat. no. sc-98502, 1:500 dilution; Santa Cruz Biotechnology, Dallas, TX) and goat polyclonal antibody human FMO3 (cat. no. sc-51288, 1:500 dilution; Santa Cruz Biotechnology) (Sakurai et al., 2013). After washing the membrane with TBS (Tris-buffered saline)-Tween (20 mM Tris-HCl, $137 \mathrm{mM}$ $\mathrm{NaCl}$, and $0.1 \%$ Tween $20 ; \mathrm{pH} 7.6$ ), resulting membranes were incubated with horseradish peroxidase-conjugated anti-rabbit IgG (cat. no. NA934, 1:20,000 dilution; GE Healthcare, Little Chalfont, Buckinghamshire, UK) and anti-goat IgG (cat. no. sc-2352, 1:20,000 dilution; Santa Cruz Biotechnology) secondary antibodies for FMO1 and FMO3, respectively. An enhanced chemiluminescence method was used to visualize the protein bands. The changes in intensity of FMO1 and FMO3 proteins were corrected using the intensity obtained in the internal control bands (glyceraldehyde-3-phosphate dehydrogenase, GAPDH). We selected GAPDH primary antibody (cat. no. ab181602, 1:2000 dilution; Abcam, Cambridge, UK) and horseradish peroxidase-conjugated anti-rabbit IgG secondary antibody (cat. no. NA934, 1:2000 dilution; GE Healthcare). Using microsomal protein preparations ranging from 10 to $60 \mu \mathrm{g} / \mathrm{lane}$, we confirmed a linear 
relationship between the abundance of FMO1 and FMO3 and staining intensity. FMO3 protein was not detectable in male mice 6-8 weeks of age. Protein content was determined by BCA protein assay (Thermo Fisher Scientific).

HPLC Assays. HPLC analysis was performed on a system equipped with a Shimadzu SPD-10A, a fluorescence detector, a UV detector, a Shimadzu LC10A pump, and a Shimadzu C-R4A chromatopac integrator (Kyoto, Japan). BDZ and its $N$-oxide were determined by the method of Ubeaud et al. (1999) with some modifications. Briefly, they were separated using a Mightysil RP-18 GP column (particle size $5 \mu \mathrm{m}, 4.6 \times 150 \mathrm{~mm}$; Kanto Chemical Co. Inc., Tokyo, Japan). Detection was performed at an excitation wavelength of $305 \mathrm{~nm}$ and an emission wavelength of $375 \mathrm{~nm}$. A mobile phase of acetonitrile and $10 \mathrm{mM}$ sodium acetate $(\mathrm{pH} 4.3)(30: 70, \mathrm{v} / \mathrm{v})$ was used at a flow rate of $1 \mathrm{ml} / \mathrm{min}$.

IMP and its $N$-oxide concentrations were determined using the method reported by Narimatsu et al. (1999) with slight modifications. Briefly, IMP and its $N$-oxide were eluted with acetonitrile- $50 \mathrm{mM}$ phosphate buffer $(\mathrm{pH} 5.5)$ $(42: 58, \mathrm{v} / \mathrm{v})$ at a flow rate of $0.8 \mathrm{ml} / \mathrm{min}$ and detected by absorbance at $254 \mathrm{~nm}$. They were separated using an Inertsil ODS column (particle size $5 \mu \mathrm{m}, 4.6 \times 150 \mathrm{~mm}$; GL Sciences Inc., Osaka, Japan).

Assay for Hepatic Inducible NO Synthase and Tumor Necrosis Factor- $\alpha$ mRNA. Total RNA was isolated from the liver using a high pure RNA tissue kit (Roche Diagnostics, Mannheim, Germany) according to the manufacturer's instructions. The concentration of total RNA in the final eluates was determined by spectrophotometry using a NanoDrop 2000 (Thermo Fisher Scientific, Waltham, MA). cDNA synthesis was performed using total RNA $(2 \mu \mathrm{g})$ in $20 \mu \mathrm{l}$ of reaction mixture consisting of Transcriptor Universal Reverse Transcriptase and Transcriptor Universal Reaction buffer (Roche Diagnostics). cDNA product was amplified by a GeneAmp PCR System 9700 (Applied Biosystems, Foster City, CA). Intronspanning, fluorescein amidite (FAM)-labeled hydrolysis probe assays were designed for genes of interest using the Universal ProbeLibrary (UPL) (Roche Diagnostics) and multiplexed with a primer-limited, VIC UPL mouse ACTB gene assay. Primer sequences for mouse inducible NOS (iNOS; forward, 5'-tggccaccaagctgaact-3'; reverse, $5^{\prime}$-ttcatgataacgtttctggctct- $\left.3^{\prime}\right)$ and mouse tumor necrosis factor $\alpha$ (TNF- $\alpha$ ) (forward, $5^{\prime}$-tggccaccaagctgaact- $3^{\prime}$; reverse, $5^{\prime}$-ttcatgataacgttctggctct- $3^{\prime}$ ). Triplicate reactions per cDNA sample were prepared using FastStar Universal Probe Master (Roche Diagnostics), $500 \mathrm{nM}$ forward primer, $500 \mathrm{nM}$ reverse primer, $250 \mathrm{nM}$ FAM-label UPL probe (\#68, cat. no. 04688678001 for iNOS; \#49, cat. no. 04688104001 for TNF- $\alpha$ ), $0.2 \mu \mathrm{l}$ VIC-labeled $\beta$-actin assay, $5 \mu \mathrm{l}$ cDNA (diluted 1:20 from stock), and DNase-free water in $20 \mu \mathrm{l}$ of reaction mixture. Amplification and detection were performed using a StepOne Plus Real Time PCR System (Thermo Fisher Scientific). Target gene expression levels were calculated after normalization to the standard housekeeping gene $\beta$-actin (UPL mouse ACTB gene assay; Roche Diagnostics). Relative expression of the gene of interest compared with $\beta$-actin expression was calculated using a standard curve of serially diluted cDNA to correct for polymerase chain reaction efficiency.

Statistical Analysis. Statistical analysis was performed by a one-way analysis of variance test, and significance was assessed using Tukey's post-hoc test.

\section{Results}

Hepatic Microsomal IMP and BDZ Metabolism. Imipramine is converted to imipramine $N$-oxide solely by FMO1 (Hernandez et al., 2009), and BDZ is metabolized to BDZ $N$-oxide by recombinant FMO1 and FMO3 isoforms (Störmer et al., 2000). Störmer et al. (2000) showed that the rates of BDZ $N$-oxide formed by recombinant CYP3A, 2C, 2D6, $1 \mathrm{~A} 2$, and $2 \mathrm{E} 1$ were one order of magnitude lower than that determined for recombinant FMO1 and FMO3 isoforms, implying a very minor contribution by P450 enzymes to BDZ N-oxygenation. In our study, PS7 (primary sensitization) and SS7 (secondary sensitization) mice did not have altered relative metabolic IMP activity (Fig. 1A). However, the relative BDZ activity was significantly decreased to $72.8 \% \pm 5.2 \%$ and $68.4 \% \pm 5.4 \%$ by PS7 and SS7, respectively (Fig. 1B). This finding on FMO1-dependent IMP metabolism may help to clarify FMO3dependent BDZ $\mathrm{N}$-oxide metabolism in hepatic microsomes.

Western Blot Analysis of Hepatic FMO1 and FMO3. The expression levels of hepatic microsomal FMO1 and FMO3 proteins were investigated by Western blot analysis (Fig. 2, A and B). In PS7 mice, protein levels of FMO1 and FMO3 enzymes were similar to those of control mice. SS7 mice had slightly reduced protein levels of FMO3, resulting in an insignificant difference between SS7 and control mice (Fig. 2B).

FMO3 mRNA expression does not change in the liver of female mice aged 6-8 weeks (Janmohamed et al., 2004). To determine if FMO3 protein changes at this age, we evaluated the abundance of FMO3 protein in untreated 6- to 8-week old female mice by Western blotting. As shown in Fig. 2C, hepatic FMO3 protein expression was not significantly different over this time period.

Hepatic iNOS and TNF- $\alpha$ mRNA Levels. Hepatic iNOS mRNA expression was determined by real-time polymerase chain reaction. The mRNA level of hepatic iNOS was significantly increased in sensitized mice compared with the corresponding control mice (Fig. 3A), resulting in an average 5-fold and 15-fold higher expression in the PS7 and SS7 mice, respectively. Further, hepatic TNF- $\alpha$ mRNA expression was significantly enhanced by type 1 allergic diseases (Fig. 3B).

Direct Effect of NO and AS on Hepatic Microsomal FMO Enzymes. We examined the direct effect of $\mathrm{NO}$ on hepatic microsomal IMP and BDZ metabolism (Fig. 4). When NOC7, an efficient NO donor, was incubated with hepatic microsomes prepared from control mice, NO overproduction did not alter IMP $N$-oxidation activity. In contrast, the inhibition degree of BDZ $N$-oxygenation activity was $36.8 \% \pm 7.4 \%$. To further characterize the suppression of BDZ-metabolic activity, we examined the involvement of cysteine thiols $S$-nitrosylation in FMO-NO
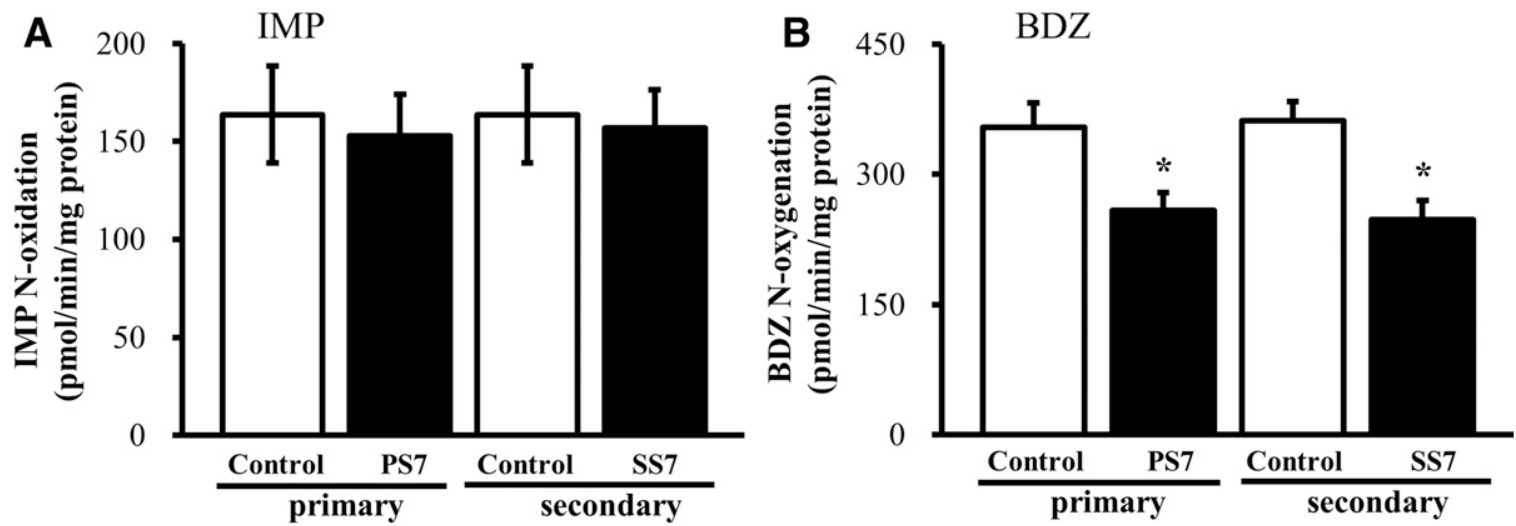

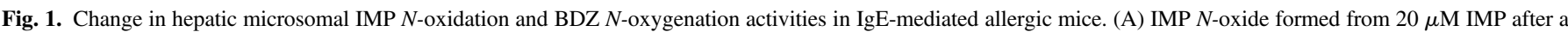

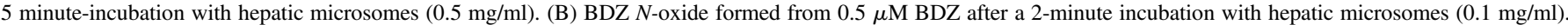

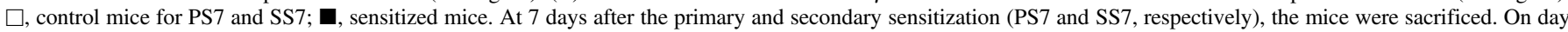

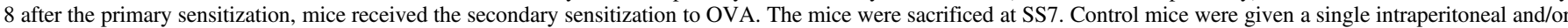
intravenous injection of saline. Data are expressed as the mean \pm S.D. of four to six mice. ${ }^{*} P<0.01$ compared with each control mouse 


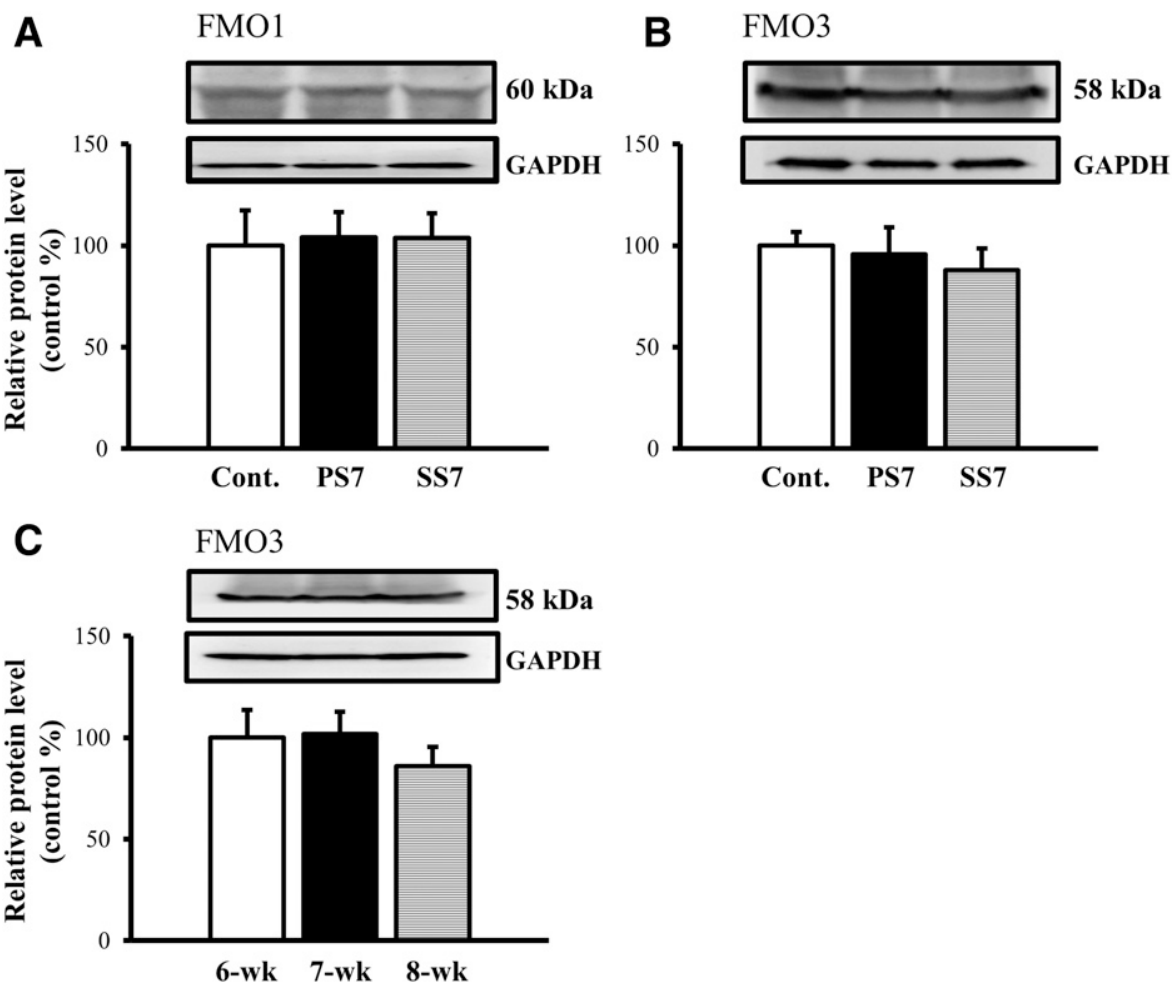

Fig. 2. Expression levels of hepatic FMO proteins. (A and B) Western blotting for hepatic microsomal FMO1 and FMO3 isoforms. Data are normalized to GAPDH bands and are representative of three independent experiments. The protein expression is expressed in terms of the percentage of the control mice (Cont) on day 7 after intraperitoneal injection of saline. (C) Expression levels of hepatic microsoma FMO3 protein in 6- to 8-week-old mice. Data are normalized to GAPDH bands. The protein expression is expressed in terms of percentage of 6-week-old mice (6-wk) before primary sensitization. 7-wk: control mice for PS7 mice. 8-wk: control mice for SS7 mice. All samples were loaded in triplicate.

interactions using AS, a sulfhydryl-reducing reagent. After the NOC7 preincubation with hepatic microsomes, AS treatment restored the suppression of BDZ metabolism to the control levels (Fig. 4B).

Preventable Effect of AS on Hepatic BDZ Metabolism in Sensitized Mice. Figure 5 shows the preventable effect of AS on hepatic microsomal BDZ metabolism suppressed by type 1 allergy. When hepatic microsomes from PS7 and SS7 mice were treated with AS, BDZ $\mathrm{N}$-oxygenation activity was completely restored to control levels.

Effect of iNOS Inhibitor on Allergy-Induced Serum NO Levels. Plasma total IgE levels at 7 days after primary or secondary sensitization were significantly elevated to $6357 \pm 1740$ and $7799 \pm 2893 \mathrm{ng} / \mathrm{ml}$, respectively, showing 60-fold higher concentrations compared with $\operatorname{IgE}$ values in control mice (Fig. 6A). The plasma total IgE level in SS7 mice did not differ from that in PS7 mice. Chronic treatment with a selective iNOS inhibitor, AG, did not alter the high IgE levels in the two sensitized mice.

PS7 and SS7 mice showed higher levels of serum nitrate plus nitrite (NOx; $3.52 \pm 0.48 \mu \mathrm{M}$ and $4.68 \pm 0.53 \mu \mathrm{M}$, respectively) compared with corresponding control mice $(0.55 \pm 0.15 \mu \mathrm{M}$ for PS7 mice and $0.61 \pm 0.17 \mu \mathrm{M}$ for SS7 mice) (Fig. 6B). PS7 mice had a similar serum
NOx concentration to SS7 mice. When AG was repeatedly injected into two sensitized mice, the high serum NOx levels observed were markedly reduced to control levels.

Hepatic Microsomal BDZ Activity in AG-Treated Sensitized Mice. We studied participation of allergy-induced NO in microsomal BDZ $N$-oxygenation activity suppressed by primary and secondary sensitization. Chronic AG treatment restored the BDZ activity suppressed in PS7 and SS7 mice (Fig. 6C). When AG was injected in salinetreated (control) mice, hepatic BDZ activity was $104.9 \% \pm 6.5 \%$ and $97.9 \% \pm 2.5 \%$ of saline-treated mice. This result indicated that AG did not interact with FMO1 and FMO3 isoforms.

\section{Discussion}

FMO enzymes play significant roles in hepatic metabolism of drugs such as nicotine, chlorpromazine, clozapine, cimetidine, and tamoxifen (Cashman et al., 1992; Mani et al., 1993; Bhamre et al., 1995; Tugnait et al., 1997). In allergic diseases, little is known about interactions between chemical mediators and FMO enzymes. Concerning allergic
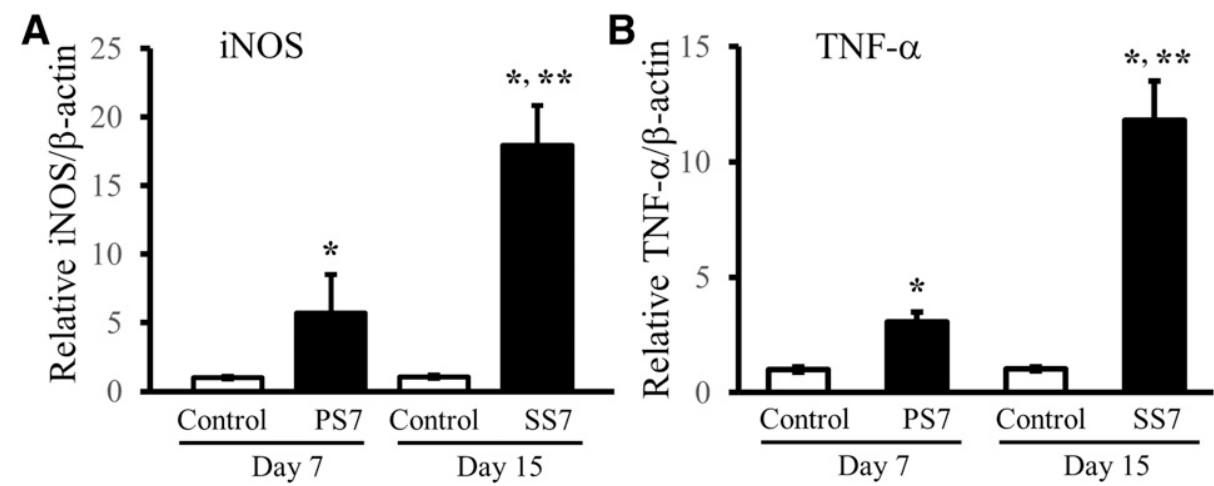

Fig. 3. Expression levels of hepatic iNOS and hepatic TNF- $\alpha$ mRNA in sensitized mice. (A) Hepatic iNOS and (B) hepatic TNF- $\alpha$ levels were determined using PCR and normalized to the $\beta$-actin mRNA level in the same sample. Data are expressed as the mean \pm S.D. $(n=3-6) . * P<0.01$, significant difference from each control mouse. ${ }^{* * P}<0.01$, significant difference from PS7 mice. 

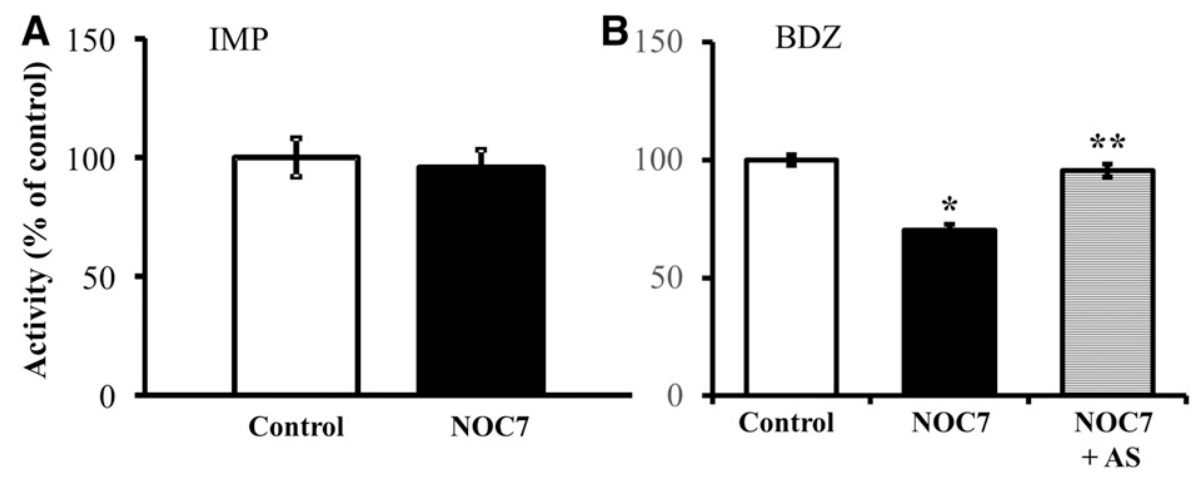

Fig. 4. Direct effect of NO and AS on IMP $N$-oxidation and BDZ $N$-oxygenation activities in untreated hepatic microsomes. IMP (A) or BDZ (B) was incubated with NOC7-pretreated hepatic microsomes. Further, after the exposure of the NOC7-treated microsomes to AS, BDZ $N$-oxygenation was determined. ${ }^{*} P<0.01$, significant difference from controls without treatment with NOC7. $* * P<0.05$, significant difference from NOC7 treatment.

disease-induced mediators, our recent study reported that the gas messenger NO markedly altered pharmacokinetics of major P450metabolic capacity-limited drugs without altering hepatic $\mathrm{P} 450$ protein levels, protein binding of drugs, and blood flow rate (Tanino et al., 2016). The altered pharmacokinetics were responsible for NO-derived post-translational suppression of hepatic $\mathrm{P} 450$ metabolic activities, with the exception of CYP2D. Therefore, our attention was focused on the interaction of hepatic microsomal FMO1 and FMO3 with type 1 allergyinduced $\mathrm{NO}$, and further on the changes in NO-produced factors in liver.

Functional FMO1, FMO3, and FMO5 proteins are expressed in the mouse liver (Cherrington et al., 1998). As shown in Fig. 2, A and B, we also confirmed the expression of hepatic FMO1 and FMO3 proteins in ICR female mice. Cherrington et al. (1998) showed that IMP was a much better substrate for FMO1 than for FMO3 and FMO5 in hepatic microsomes of mice. Furthermore, in FMO1 gene-deficient mice, the FMO1 isoform plays an important role in IMP metabolism (Hernandez et al., 2009). Therefore, we selected IMP as a mouse FMO1 substrate. Concerning FMO3 substrates, BDZ is often used as an in vitro probe of human and mouse FMO3-dependent metabolism (Fisher et al., 2002). The recombinant FMO3 enzyme showed a one-half lower $\mathrm{V}_{\max }$ (maximal velocity)/ $\mathrm{K}_{\mathrm{m}}$ (Michaelis-Menten constant) value (intrinsic clearance) in BDZ $\mathrm{N}$-oxide formation than the recombinant FMO1 enzyme (Störmer et al., 2000). The recombinant FMO5 enzyme does not participate in BDZ metabolism. In recombinant human FMO3, trimethylamine, methimazole, and tozasertib strongly suppress BDZ $N$-oxygenation activity by $40-50 \%$ among well known 41 FMO3 substrates, including cimetidine and nicotine (Shimizu et al., 2015). However, Siddens et al. (2008) showed that methimazole was metabolized by mouse FMO1, FMO2, and FMO3. Tozaserib, as well as BDZ, is reported to be a probe for FMO1 and FMO3 in humans and experimental animals (Yamazaki et al., 2014). As far as we know, FMO3-specific substrates, with an exception for endogenous trimethylamine, have not been reported in mice. Unfortunately, since we had no instruments for trimethylamine analysis, FMO3 activity was estimated from the data of BDZ $N$-oxygenation and specific IMP oxidation.

Unlike microsomal IMP-metabolic activity, PS7 and SS7 mice showed differential suppression of hepatic microsomal BDZ-metabolic activity, showing around 30\% inhibition (Fig. 1). In Western blot analysis, primary and secondary sensitization did not significantly alter the expression level of the FMO1 and FMO3 proteins (Fig. 2). Park et al. (1999) showed that hepatic FMO1 enzyme activity and contents were greatly suppressed by lipopolysaccharide (LPS), and this was at least partially prevented by treatment with inducible NOS (iNOS) inhibitor. The targets of LPS in upregulating hepatic NO release are considered to be Kupffer and endothelial cells (Spolarics et al., 1993). In Citrobacter rodentium-treated mice of a different inflammatory model, hepatic FMO1 and FMO3 mRNA levels were markedly downregulated at day 10 post-treatment to 42 and $0.6 \%$ of controls, respectively (Zhang et al., 2009). These findings in T helper 1 cell-dependent inflammatory diseases differed from our data that showed no changes in protein expression and activity of microsomal FMO1 (Figs. 1 and 2). In this study, the differential suppression of FMO3 activity may be type 1 allergic disease-dependent. In differential suppression mechanism(s), it remains unclear whether direct cytokine stimulation and/or NO-releasing pathway prefer to suppress hepatic BDZ metabolism with irreversible and/or reversible inhibition.
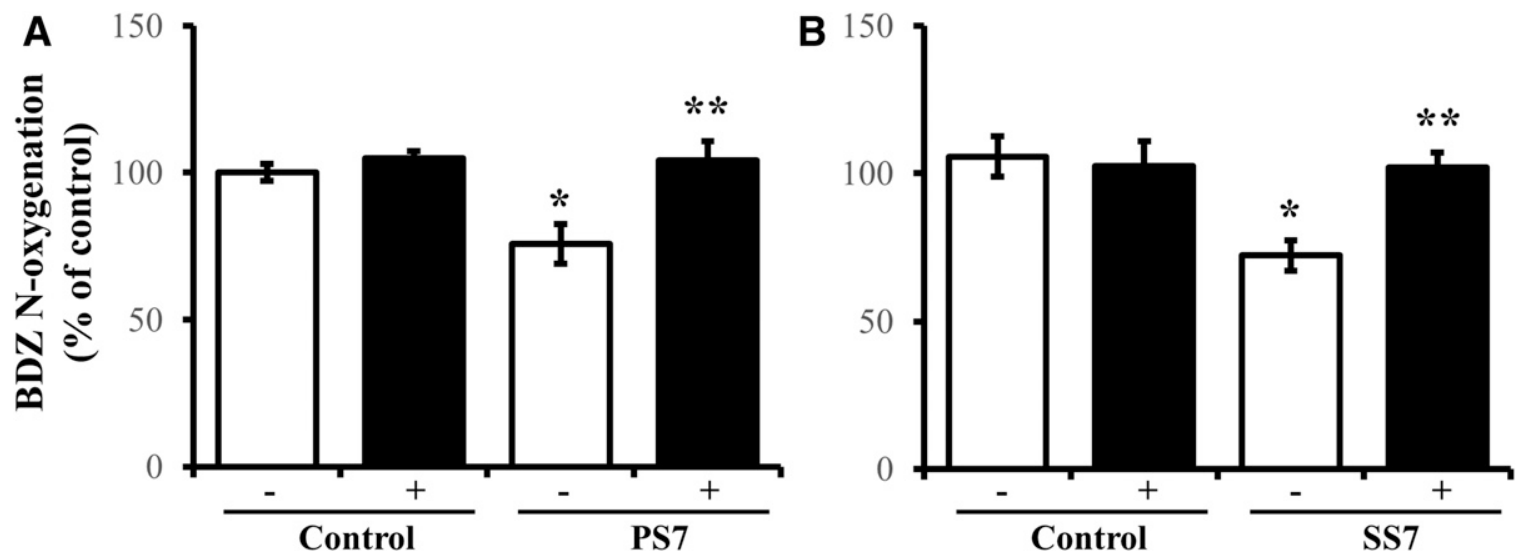

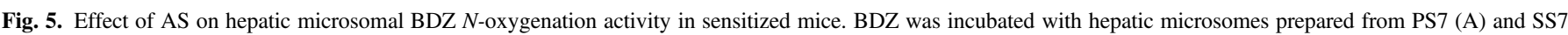

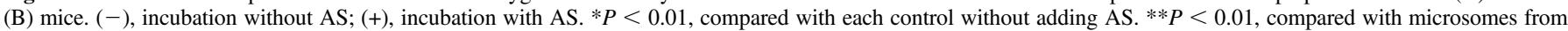
PS7 and SS7 mice in the absence of AS. Data are expressed as the mean \pm S.D. of four mice. 

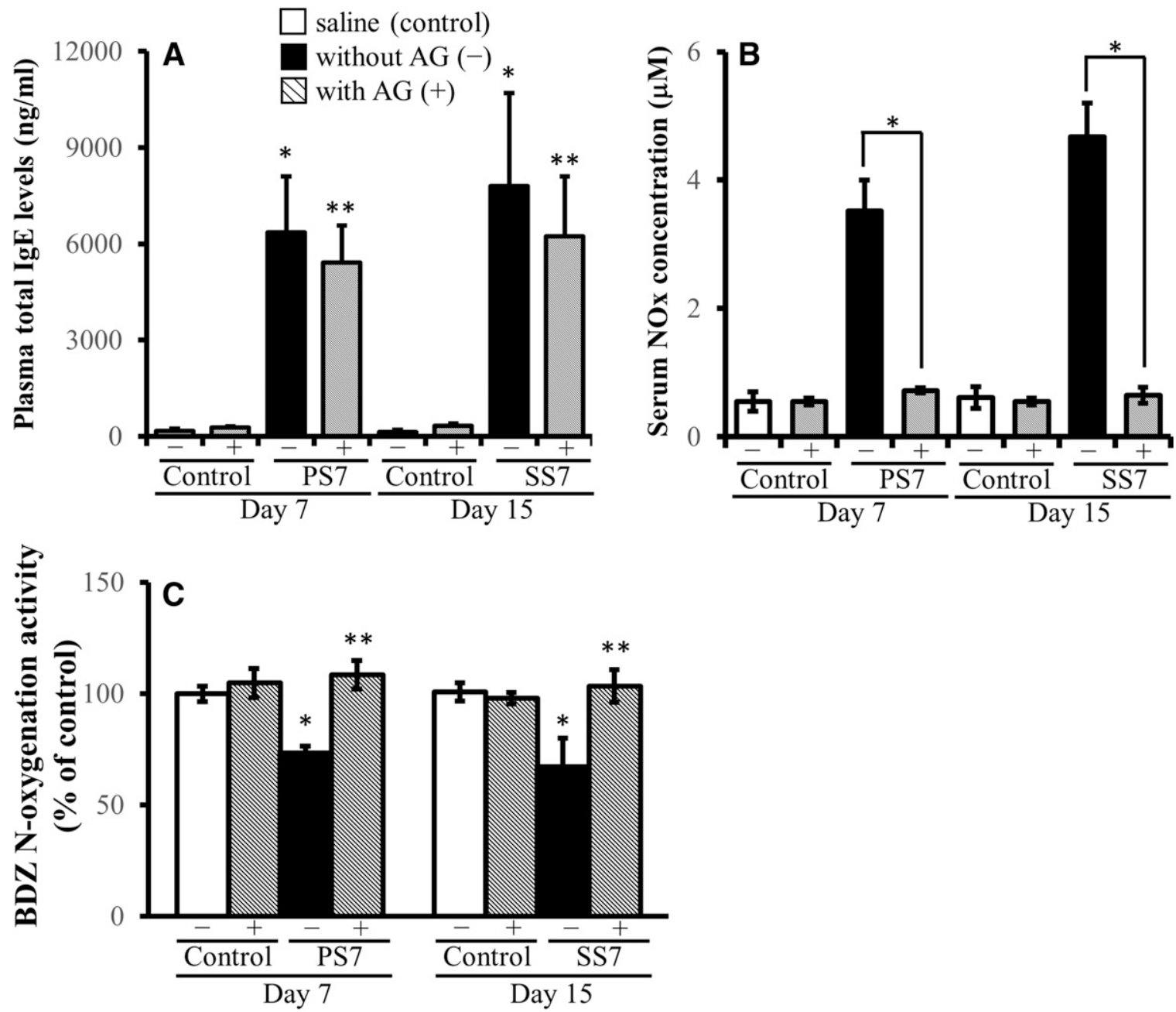

Fig. 6. Change in the total plasma IgE level, serum NO concentration, and hepatic metabolic activity in AG-treated PS7 and SS7 mice. Data are expressed as the mean \pm S.D. of four to six mice. (A) Total plasma IgE concentration. $* P<0.01$, significant difference from each control mouse without AG $(-)$. *** $P<0.01$, significant difference from each control mouse with AG (+). (B) Serum NOx level. $* P<0.01$, significant difference from PS7 or SS7 mice without AG (-). (C) Hepatic microsomal BDZ activity in PS7 and SS7 mice treated with AG (+) or without AG (-). PS7 and SS7 mice were repeatedly injected with AG (100 mg/kg per day, i.p.) from day 2 to day 7 or to day 14 after the primary sensitization, respectively. ${ }^{*} P<0.01$, significant difference from each control mouse without AG $(-)$. $* * P<0.01$, significant difference from PS7 or SS7 mice without AG (-).

The serum NO level was significantly enhanced by type 1 allergic diseases (Fig. 5B). In general, NO is released from the vascular endothelium, Kupffer cells, platelets, mast cells, macrophages, nerve endings, and the brain (Garthwaite et al., 1988; Knowles et al., 1990). NO is a small, unchanged free radical that diffuses freely in and out of cells and between cellular compartments (Coleman, 2001). Excess NO can modify the functions of various proteins with haem-nitrosylation, $S$-nitrosylation (S-NO binding with cysteine thiols), and tyrosine nitration, implying posttranslational modifications. When we evaluated the direct interaction of FMO1 and FMO3 with NO in hepatic microsomes from saline-treated mice, IMP $N$-oxidation activity was not suppressed by NO overproduction; however, BDZ $N$-oxide activity was significantly suppressed (Fig. 4). The differential suppression seemed to cause FMO3-dependent BDZ metabolism rather than FMO1-dependent BDZ metabolism. Additionally, the NO-derived inhibition capability and differential suppression may explain the changes in BDZ metabolic activity observed in PS7 and SS7 mice (Fig. 1). Ryu et al. (2004) showed that recombinant human FMO3 activity (substrates: ranitidine, trimethylamine, and thiobenzamide) was directly suppressed by NO donors (SNP, SNAP, and Sin-1), resulting in an increase in FMO3 activity by incubation with AS. We were interested in reversible and/or irreversible inhibition(s) of microsomal BDZ metabolism downregulated by NO overproduction. As shown in Fig. 4B, the direct NO-derived interaction was markedly reduced by AS treatment at an effective dose. Another reducing regent for $-\mathrm{S}-\mathrm{S}$ adduct, dithiothreitol, did not restore NO-derived BDZ $N$-oxygenation activity to control level (data not shown). Unlike P450 enzymes, FMO enzymes cannot produce iron-nitrosyl complexes in molecules (Minamiyama et al., 1997). Since AS reduces $S$-nitroso adduct (S-NO adduct) only (Xian et al., 2000), we speculated that the direct effect of NO was related to protein $S$-nitrosyl cysteine but not nitration of protein tyrosine residues (irreversible and stable adducts known as a marker of NO-mediated tissue damage), possibly leading to reversible suppression of FMO3-dependent BDZ activity. Protein $S$-nitrosylation is reported to be enhanced by NOS activation (Iwakiri and Kim, 2015). In this study, we performed the AS treatment to characterize a suppression mechanism of FMO3-metabolic BDZ activity.

The hepatic NOS family is classified as constitutively expressed endothelial NOS (eNOS), neuronal NOS, and iNOS (Knowles et al., 1990). Eum et al. (2006) showed that iNOS-derived NO mediated hepatocellular damage. Hepatic eNOS is mainly expressed in sinusoidal endothelial cells and endothelial cells of the hepatic artery, portal vein, and central vein (McNaughton et al., 2002; Iwakiri and Kim, 2015). 
Miyoshi et al. (2005) reported that iNOS played an important role in the elevation of plasma NOx by endotoxin, although the slight NOx elevation in plasma of TNF- $\alpha^{-/-}$mice was induced by eNOS enzyme. During endotoxemic shock and LPS-stimulated inflammation ( $\mathrm{T}$ helper 1-dependent pathway), it is believed that Kupffer cells are the main source of NO (Alexander, 1998). Of interest, Takagi et al. (2007) demonstrated that hepatic iNOS expression was completely absent in TNF- $\alpha^{-1-}$ mice. Bidri et al. (2001) showed that mast cells elicited sustained NO production, possibly through participation of a positive amplification loop via TNF- $\alpha$ release, since FceRI-triggering induces TNF- $\alpha$ release (Gordon and Galli, 1991). Concerning other iNOSstimulated cytokines, IL-1 is not essential for the induction of iNOS in hepatocytes of IL- $1 \alpha / \beta$ double-knockout mice (Takagi et al., 2007). IL- $1 \beta$, IL-6, and interferon- $\gamma$ are well known to suppress the protein levels and activities of CYP1A2, CYP2C, CYP2E1, and CYP3A (Abdel-Razzak et al., 1993), differing completely with our recent data (Tanino et al., 2016). Therefore, we focused on hepatic TNF- $\alpha$ activation among the iNOSstimulated cytokines. As shown in Fig. 3B, PS7 and SS7 mice showed a 4-fold and 10-fold increase in hepatic TNF- $\alpha$ mRNA levels, respectively. Although iNOS is not constitutively expressed under normal conditions, PS7 and SS7 mice showed significantly enhanced hepatic iNOS mRNA levels (Fig. 3A). These results may be helpful in understanding an $\mathrm{NO}$-produced pathway of the allergy-suppressed BDZ $\mathrm{N}$-oxide activity. We further evaluated iNOS-dependent NO production in type 1 allergic mice. In PS7 and SS7 mice, a selective iNOS inhibitor, AG, completely suppressed the high serum NO levels (Fig. 6B), and restored BDZ $N$-oxide activity to control levels (Fig. 6C). After AS was incubated with hepatic microsomes from PS7 and SS7 mice, BDZ $N$-oxygenation returned to control levels (Fig. 5). Therefore, our results suggest that iNOS-derived NO participates in the formation of reversible-S-NO adducts, resulting in BDZ $N$-oxide activity suppressed in type 1 allergic mice.

In conclusion, we showed that the onset of IgE-mediated allergic diseases differentially suppressed the metabolic activity of clinically significant FMO3 enzyme. This differential suppression related to posttranslational interaction (cysteine-thiols $S$-nitrosylation) with NO overproduced by hepatic iNOS activation, and our findings may suggest marked changes in hepatic FMO3-metabolic capacity-limited drug pharmacokinetics. This study would provide a first step toward clarifying the mechanisms of drug-disease interactions in allergic diseases via the $\mathrm{T}$ helper 2 cell-dependent pathway.

\section{Authorship Contributions}

Participated in research design: Tanino, Sakurai.

Conducted experiments: Tanino, Komada, Bando, Nojiri, Okada, Ueda.

Performed data analysis: Tanino, Komada, Bando, Nojiri, Okada, Ueda.

\section{References}

Abdel-Razzak Z, Loyer P, Fautrel A, Gautier JC, Corcos L, Turlin B, Beaune P, and Guillouzo A (1993) Cytokines down-regulate expression of major cytochrome P-450 enzymes in adult human hepatocytes in primary culture. Mol Pharmacol 44:707-715.

Alexander B (1998) The role of nitric oxide in hepatic metabolism. Nutrition 14:376-390.

Alving K, Weitzberg E, and Lundberg JM (1993) Increased amount of nitric oxide in exhaled air of asthmatics. Eur Respir J 6:1368-1370.

Bhamre S, Bhagwat SV, Shankar SK, Boyd MR, and Ravindranath V (1995) Flavin-containing monooxygenase mediated metabolism of psychoactive drugs by human brain microsomes. Brain Res 672:276-280.

Bidri M, Féger F, Varadaradjalou S, Ben Hamouda N, Guillosson JJ, and Arock M (2001) Mast cells as a source and target for nitric oxide. Int Immunopharmacol 1:1543-1558.

Cashman JR and Zhang J (2006) Human flavin-containing monooxygenases. Annu Rev Pharmacol Toxicol 46:65-100.

Cashman JR, Park SB, Yang ZC, Wrighton SA, Jacob P, III, and Benowitz NL (1992) Metabolism of nicotine by human liver microsomes: stereoselective formation of trans-nicotine $\mathrm{N}^{\prime}$-oxide. Chem Res Toxicol 5:639-646.

Cherrington NJ, Cao Y, Cherrington JW, Rose RL, and Hodgson E (1998) Physiological factors affecting protein expression of flavin-containing monooxygenases 1, 3 and 5. Xenobiotica 28:673-682.

Coecke S, Debast G, Phillips IR, Vercruysse A, Shephard EA, and Rogiers V (1998) Hormona regulation of microsomal flavin-containing monooxygenase activity by sex steroids and growth hormone in co-cultured adult male rat hepatocytes. Biochem Pharmacol 56:1047-1051.
Coleman JW (2001) Nitric oxide in immunity and inflammation. Int Immunopharmacol 1:1397-1406.

Dannan GA, Guengerich FP, and Waxman DJ (1986) Hormonal regulation of rat liver microsomal enzymes. Role of gonadal steroids in programming, maintenance, and suppression of delta 4-steroid 5 alpha-reductase, flavin-containing monooxygenase, and sex-specific cytochromes P-450. J Biol Chem 261:10728-10735.

Dixit A and Roche TE (1984) Spectrophotometric assay of the flavin-containing monooxygenase and changes in its activity in female mouse liver with nutritional and diurnal conditions. Arch Biochem Biophys 233:50-63.

Dolphin CT, Beckett DJ, Janmohamed A, Cullingford TE, Smith RL, Shephard EA, and Phillips IR (1998) The flavin-containing monooxygenase 2 gene (FMO2) of humans, but not of other primates, encodes a truncated, nonfunctional protein. J Biol Chem 273:30599-30607.

Dolphin CT, Cullingford TE, Shephard EA, Smith RL, and Phillips IR (1996) Differential developmental and tissue-specific regulation of expression of the genes encoding three members of the flavin-containing monooxygenase family of man, FMO1, FMO3 and FM04. Eur J Biochem 235:683-689.

Esposito T, Varriale B, D'Angelo R, Amato A, and Sidoti A (2014) Regulation of flavin-containing mono-oxygenase (Fmo3) gene expression by steroids in mice and humans. Horm Mol Biol Clin Investig 20:99-109.

Eum HA, Yeom DH, and Lee SM (2006) Role of nitric oxide in the inhibition of liver cytochrome P450 during sepsis. Nitric Oxide 15:423-431.

Falls JG, Ryu DY, Cao Y, Levi PE, and Hodgson E (1997) Regulation of mouse liver flavincontaining monooxygenases 1 and 3 by sex steroids. Arch Biochem Biophys 342:212-223.

Fisher MB, Yoon K, Vaughn ML, Strelevitz TJ, and Foti RS (2002) Flavin-containing monooxygenase activity in hepatocytes and microsomes: in vitro characterization and in vivo scaling of benzydamine clearance. Drug Metab Dispos 30:1087-1093.

Garthwaite J, Charles SL, and Chess-Williams R (1988) Endothelium-derived relaxing factor release on activation of NMDA receptors suggests role as intercellular messenger in the brain Nature 336:385-388.

Gordon JR and Galli SJ (1991) Release of both preformed and newly synthesized tumor necrosis factor alpha (TNF-alpha)/cachectin by mouse mast cells stimulated via the Fc epsilon RI. A mechanism for the sustained action of mast cell-derived TNF-alpha during IgE-dependent biological responses. J Exp Med 174:103-107.

Haining RL, Hunter AP, Sadeque AJM, Philpot RM, and Rettie AE (1997) Baculovirus-mediated expression and purification of human FMO3: catalytic, immunochemical, and structural characterization. Drug Metab Dispos 25:790-797.

Hernandez D, Janmohamed A, Chandan P, Omar BA, Phillips IR, and Shephard EA (2009) Deletion of the mouse Fmol gene results in enhanced pharmacological behavioural responses to imipramine. Pharmacogenet Genomics 19:289-299.

Iwakiri Y and Kim MY (2015) Nitric oxide in liver diseases. Trends Pharmacol Sci 36:524-536.

Janmohamed A, Hernandez D, Phillips IR, and Shephard EA (2004) Cell-, tissue-, sex- and developmental stage-specific expression of mouse flavin-containing monooxygenases (Fmos). Biochem Pharmacol 68:73-83.

Kharitonov SA, Rajakulasingam K, O'Connor B, Durham SR, and Barnes PJ (1997) Nasal nitric oxide is increased in patients with asthma and allergic rhinitis and may be modulated by nasa glucocorticoids. J Allergy Clin Immunol 99:58-64.

Knowles RG, Merrett M, Salter M, and Moncada S (1990) Differential induction of brain, lung and liver nitric oxide synthase by endotoxin in the rat. Biochem $J$ 270:833-836.

Koukouritaki SB, Simpson P, Yeung CK, Rettie AE, and Hines RN (2002) Human hepatic flavin-containing monooxygenases 1 (FMO1) and 3 (FMO3) developmental expression. Pediatr Res 51:236-243.

Krueger SK and Williams DE (2005) Mammalian flavin-containing monooxygenases: structure/function, genetic polymorphisms and role in drug metabolism. Pharmacol Ther 106:357-387.

Lebrec H, Sarlo K, and Burleson GR (1996) Effect of influenza virus infection on ovalbuminspecific IgE responses to inhaled antigen in the rat. J Toxicol Environ Health 49:619-630.

Lemoine A, Williams DE, Cresteil T, and Leroux JP (1991) Hormonal regulation of microsomal flavin-containing monooxygenase: tissue-dependent expression and substrate specificity. Mol Pharmacol 40:211-217.

Mani C, Hodgson E, and Kupfer D (1993) Metabolism of the antimammary cancer antiestrogenic agent tamoxifen. II. Flavin-containing monooxygenase-mediated N-oxidation. Drug Metab Dispos 21:657-661.

McNaughton L, Puttagunta L, Martinez-Cuesta MA, Kneteman N, Mayers I, Moqbel R, Hamid Q, and Radomski MW (2002) Distribution of nitric oxide synthase in normal and cirrhotic human liver. Proc Natl Acad Sci USA 99:17161-17166.

Minamiyama Y, Takemura S, Imaoka S, Funae Y, Tanimoto Y, and Inoue M (1997) Irreversible inhibition of cytochrome P450 by nitric oxide. J Pharmacol Exp Ther 283:1479-1485.

Miyoshi M, Nadai M, Nitta A, Ueyama J, Shimizu A, Takagi K, Nabeshima T, Takagi K, Saito K, and Hasegawa $\mathrm{T}$ (2005) Role of tumor necrosis factor-alpha in down-regulation of hepatic cytochrome P450 and P-glycoprotein by endotoxin. Eur J Pharmacol 507:229-237.

Morgan ET, Goralski KB, Piquette-Miller M, Renton KW, Robertson GR, Chaluvadi MR, Charles KA, Clarke SJ, Kacevska M, Liddle C, et al. (2008) Regulation of drug-metabolizing enzymes and transporters in infection, inflammation, and cancer. Drug Metab Dispos 36:205-216.

Narimatsu S, Yamamoto S, Kato R, Masubuchi Y, and Horie T (1999) Contribution of flavincontaining monooxygenase and cytochrome P450 to imipramine N-oxidation in rat hepatic microsomes. Biol Pharm Bull 22:567-571.

Novick RM, Mitzey AM, Brownfield MS, and Elfarra AA (2009) Differential localization of flavin-containing monooxygenase (FMO) isoforms 1,3 , and 4 in rat liver and kidney and evidence for expression of FMO4 in mouse, rat, and human liver and kidney microsomes. J Pharmacol Exp Ther 329:1148-1155.

Okuda Y, Sakoda S, Fujimura H, and Yanagihara T (1998) Aminoguanidine, a selective inhibitor of the inducible nitric oxide synthase, has different effects on experimental allergic encephalomyelitis in the induction and progression phase. J Neuroimmunol 81:201-210.

Park CS, Baek HM, Chung WG, Lee KH, Ryu SD, and Cha YN (1999) Suppression of flavincontaining monooxygenase by overproduced nitric oxide in rat liver. Mol Pharmacol 56: 507-514.

Pauwels R, Bazin H, Platteau B, and Van Der Straeten M (1979) The influence of different adjuvants on the production of IgD and IgE antibodies. Ann Immunol (Paris) 130C:49-58

Renton KW (2001) Alteration of drug biotransformation and elimination during infection and inflammation. Pharmacol Ther 92:147-163.

Renton KW (2004) Cytochrome P450 regulation and drug biotransformation during inflammation and infection. Curr Drug Metab 5:235-243. 
Rettie AE, Meier GP, and Sadeque AJM (1995) Prochiral sulfides as in vitro probes for multiple forms of the flavin-containing monooxygenase. Chem Biol Interact 96:3-15.

Ryu SD, Yi HG, Cha YN, Kang JH, Kang JS, Jeon YC, Park HK, Yu TM, Lee JN, and Park CS (2004) Flavin-containing monooxygenase activity can be inhibited by nitric oxide-mediated S-nitrosylation. Life Sci 75:2559-2572.

Sakurai E, Ueda Y, Mori Y, Shinmyouzu Y, and Sakurai E (2013) Flavin-containing monooxygenase (FMO) protein expression and its activity in rat brain microvascular endothelial cells. Pharmacol Pharm 4:1-6.

Shimizu M, Shiraishi A, Sato A, Nagashima S, and Yamazaki H (2015) Potential for drug interactions mediated by polymorphic flavin-containing monooxygenase 3 in human livers. Drug Metab Pharmacokinet 30:70-74.

Siddens LK, Henderson MC, Vandyke JE, Williams DE, and Krueger SK (2008) Characterization of mouse flavin-containing monooxygenase transcript levels in lung and liver, and activity of expressed isoforms. Biochem Pharmacol 75:570-579.

Spolarics Z, Spitzer JJ, Wang JF, Xie J, Kolls J, and Greenberg S (1993) Alcohol administration attenuates LPS-induced expression of inducible nitric oxide synthase in Kupffer and hepatic endothelial cells. Biochem Biophys Res Commun 197:606-611.

Stassen M, Müller C, Arnold M, Hültner L, Klein-Hessling S, Neudörfl C, Reineke T, Serfling E, and Schmitt E (2001) IL-9 and IL-13 production by activated mast cells is strongly enhanced in the presence of lipopolysaccharide: NF-kappa B is decisively involved in the expression of IL-9. J Immunol 166:4391-4398.

Störmer E, Roots I, and Brockmöller J (2000) Benzydamine N-oxidation as an index reaction reflecting FMO activity in human liver microsomes and impact of FMO3 polymorphisms on enzyme activity. Br J Clin Pharmacol 50:553-561.

Takagi K, Matsumura S, Okuda-Ashitaka E, Okuda K, Watanabe J, Takahashi H, Iwakura Y, and Ito S (2007) Interleukin-1 is not essential for expression of inducible NOS in hepatocytes induced by lipopolysaccharide in vivo. Nitric Oxide 16:433-441.

Tanino T, Komada A, Ueda K, Bando T, Nojiri Y, Ueda Y, and Sakurai E (2016) Pharmacokinetics and differential regulation of cytochrome P450 enzymes in type 1 allergic mice. Drug Metab Dispos 44:1950-1957.

Treacy EP, Akerman BR, Chow LML, Youil R, Bibeau C, Lin J, Bruce AG, Knight M, Danks DM, Cashman JR, et al. (1998) Mutations of the flavin-containing monooxygenase gene (FMO3) cause trimethylaminuria, a defect in detoxication. Hum Mol Genet 7:839-845.
Tugnait M, Hawes EM, McKay G, Rettie AE, Haining RL, and Midha KK (1997) N-oxygenation of clozapine by flavin-containing monooxygenase. Drug Metab Dispos 25:524-527.

Ubeaud G, Schiller CD, Hurbin F, Jaeck D, and Coassolo P (1999) Estimation of flavin-containing monooxygenase activity in intact hepatocyte monolayers of rat, hamster, rabbit, dog and human by using N-oxidation of benzydamine. Eur J Pharm Sci 8:255-260.

Warner JO, Kaliner MA, Crisci CD, Del Giacco S, Frew AJ, Liu GH, Maspero J, Moon HB, Nakagawa T, Potter PC, et al.; World Allergy Organization Specialty and Training Council (2006) Allergy practice worldwide: a report by the world allergy organization specialty and training council. Int Arch Allergy Immunol 139:166-174.

Xian M, Chen X, Liu Z, Wang K, and Wang PG (2000) Inhibition of papain by S-nitrosothiols. Formation of mixed disulfides. J Biol Chem 275:20467-20473.

Yamazaki M, Shimizu M, Uno Y, and Yamazaki H (2014) Drug oxygenation activities mediated by liver microsomal flavin-containing monooxygenases 1 and 3 in humans, monkeys, rats, and minipigs. Biochem Pharmacol 90:159-165.

Zhang J, Cerny MA, Lawson M, Mosadeghi R, and Cashman JR (2007) Functional activity of the mouse flavin-containing monooxygenase forms 1, 3, and 5. J Biochem Mol Toxicol 21:206-215.

Zhang J, Chaluvadi MR, Reddy R, Motika MS, Richardson TA, Cashman JR, and Morgan ET (2009) Hepatic flavin-containing monooxygenase gene regulation in different mouse inflammation models. Drug Metab Dispos 37:462-468.

Zhu Z, Homer RJ, Wang Z, Chen Q, Geba GP, Wang J, Zhang Y, and Elias JA (1999) Pulmonary expression of interleukin-13 causes inflammation, mucus hypersecretion, subepithelial fibrosis, physiologic abnormalities, and eotaxin production. J Clin Invest 103:779-788.

Ziegler DM (1993) Recent studies on the structure and function of multisubstrate flavin-containing monooxygenases. Annu Rev Pharmacol Toxicol 33:179-199.

Address correspondence to: Dr. Eiichi Sakurai, Laboratory of Pharmaceutics, Faculty of Pharmaceutical Sciences, Tokushima Bunri University, 180 Bouji Nishihama, Yamashiro-Cho, Tokushima 770-8514, Japan. E-mail: esakurai@ ph.bunri-u.ac.jp 